\title{
The Impact of Nutritional Status on Health-Related Quality of Life in Hemodialysis Patients
}

\section{Lucia Visiedo ( $\square$ lucia_visiedo2_13@hotmail.com )}

Pharmacy and Nutrition Unit of the Costa del Sol Healthcare Agency

\section{Laura Rey}

Pharmacy and Nutrition Unit of the Costa del Sol Healthcare Agency

\section{Francisco Rivas}

Research and Innovation Unit of the Costa del Sol Healthcare Agency

Francisca López

Nephrology Unit of the Costa del Sol Healthcare Agency

\section{Begoña Tortajada}

Pharmacy and Nutrition Unit of the Costa del Sol Healthcare Agency

\section{Rafael Giménez}

Department of Nutrition and Bromatology, University of Granada

Jimena Abilés

Pharmacy and Nutrition Unit of the Costa del Sol Healthcare Agency

\section{Research Article}

Keywords: Nutritional risk, Malnutrition, Quality of life, Hemodialysis

Posted Date: October 25th, 2021

DOI: https://doi.org/10.21203/rs.3.rs-991513/v1

License: (c) (i) This work is licensed under a Creative Commons Attribution 4.0 International License. Read Full License

Version of Record: A version of this preprint was published at Scientific Reports on February 22nd, 2022. See the published version at https://doi.org/10.1038/s41598-022-07055-0. 


\section{Abstract}

Background: Malnutrition is frequent in hemodialysis (HD) patients. Nutritional deficiencies may negatively impact quality of life (QOL). A nutritional intervention program (NIP) to identify and intervene in patients with nutritional problems may positively influence QOL.

Methods: This study examines the utility of the Malnutrition-Inflammation Score (MIS) in detecting nutritional risk (NR) and assesses the correlation between nutritional status and QOL in dialysis patients upon starting a NIP. One hundred and twenty patients were included in this cross-sectional study. The MIS was used to detect NR and the Kidney Disease Quality of Life (KDQOL-SF ${ }^{\mathrm{TM}}$ ) instrument version 1.2 was used to assess QOL.

Results: $62 \%$ of patients were found to be at NR (MIS $>5)$. Nutritional status was significantly correlated with all generic QOL sub-scales. On a multiple linear regression analysis, malnutrition showed the highest level of explanation in the Kidney Disease Summary Component which explained $28.9 \%$ of the variance; the Physical Component Summary which explained $33 \%$ of the variance; and the Mental Component Summary which explained $21.5 \%$ of the variance.

Conclusion: Malnutrition was found to be the most significant predictor of impaired scores on the KDQOL-SF ${ }^{\mathrm{TM}}$. The use of MIS to identify patients at NR and a nutritional assessment to detect malnutrition in its early stages are important given the effects a NIP can have on improving QOL in HD patients.

\section{Introduction}

Malnutrition is frequent among patients with end-stage kidney disease receiving hemodialysis (HD). Its prevalence in HD patients ranges from 18\%-75\% [1]. Maintenance HD entails a risk of malnutrition due to the catabolic effects of this renal replacement therapy, inadequate dietary intake due to the uremic environment, loss of nutrients through the dialysis membrane, inflammation, and metabolic acidosis, which can lead to protein energy wasting (PEW) syndrome $[2,3]$.

Malnutrition is associated with an increase in morbidity, a decrease in functional capacity, and a greater number and duration of hospital admissions, all of which may cause a low health-related quality of life (QOL) and impact patients' emotional, physical, and psychosocial health. It has been described that malnourished patients have a worse QOL and thus, the early diagnosis and treatment of malnutrition is important $[4,5]$. Although nutritional status has been shown to impact QOL in HD patients, there is a limited body of evidence supporting this relationship.

In 2017, the Pharmacy and Nutrition and Nephrology Department at our hospital designed and implemented a nutritional care model for HD patients to enable the early detection of nutritional risk (NR), facilitate periodic nutritional assessment and monitoring, and implement a nutritional intervention program (NIP) at early stages prior to the onset of malnutrition so as to prevent further deterioration in QOL.

This study aims to examine the utility of the Malnutrition-Inflammation Score (MIS) in detecting NR and to describe the relationship between nutritional status and QOL in HD patients using the MIS and Kidney Disease Quality of Life $\left(\mathrm{KDQOL} \mathrm{SF}^{\mathrm{TM}}\right.$ ) instrument version 1.2 at the beginning of a NIP.

\section{Materials And Methods STUDY POPULATION}


A total of 120 patients attended to at the Costa del Sol Hospital were included. Participants met the following inclusion criteria: adults (18 years or older) who had not previously consulted with a dietician and who had been in the HD program for at least three months. HD sessions were held three times per week for four hours. No participants dropped out of the study following the intervention.

\section{Ethical approval}

was granted by Costa del Sol Research Ethics Committee on May 30, 2020 with approval number 85-05-2019. The ethical principles set forth in the most recent version of the Declaration of Helsinki and the standards of good clinical practice were adhered to. All participants signed an informed consent form prior to their inclusion in the study.

\section{STUDY DESIGN}

In this descriptive study, the nutritional care model for HD patients began with a complete nutritional assessment of food intake and symptoms that could affect nutritional status and QOL, in accordance with the clinical guidelines of The National Kidney Foundation's Kidney Disease Outcomes Quality Initiative on nutritional support for HD patients [6]. The type and degree of malnutrition observed determined the NIP indicated, which ranged from nutritional counseling to specialized nutritional support.

As per our hospital's protocol, the MIS questionnaire is administered every three months and the KDQOL-SF ${ }^{\mathrm{TM}}$ is administered twice a year. Both are performed at the beginning of HD sessions by nutritionists and trained nursing assistants who work in the Nephrology Unit. Blood samples are taken at the beginning of the HD session.

\section{Malnutrition-Inflammation Score}

The MIS was used to determine NR and a nutritional assessment was subsequently used to establish a nutritional diagnosis. Following its calculation, patients were categorized as well-nourished or malnourished. Malnourished patients were then classified as having mild, moderate, or severe protein-energy malnutrition or protein malnutrition.

Although several methods have been used to assess nutritional status in HD patients, there is no gold standard technique. The MIS, described by Kalantar et al. [7], uses components of the conventional Subjective Global Assessment (SGA) [8] and also includes comorbidity according to time on HD as well as biochemical parameters such as albumin, total iron-binding capacity, and transferrin. The MIS has four sections: nutritional history, physical examination, body mass index, and laboratory values. Total scores range from 0 to 30 points and scores $>5$ indicate the presence of NR. The MIS is widely used in CKD patients $[9,10]$, is supported by studies which have demonstrated its value as a predictor of mortality and morbidity in $\mathrm{HD}$ patients $[11,12,13]$, and is a useful tool for detecting PEW in CKD patients [14].

\section{Quality of life}

QOL was measured using validated Spanish version of the KDQOL-SF ${ }^{\mathrm{TM}}$ version 1.2 [15]. It includes 43 specific items for patients with kidney disease organized into 11 specific dimensions of the disease. They include symptom/problem list, effects of kidney disease, burden of kidney disease, work status, cognitive function, quality of social interaction, sexual function, sleep, social support, dialysis staff encouragement, and patient satisfaction. All of these 
aforementioned items form part of the kidney disease summary component (KDSC). Furthermore, the KDQOL-SF ${ }^{\mathrm{TM}}$ also includes a section with the 36 generic items of the SF-36 questionnaire. It is organized into eight dimensions and two summary scores: the physical component summary (PCS) and the mental component summary (MCS) scores. Items include physical functioning, role-physical, pain, general health, emotional well-being, role-emotional, social function, and energy/fatigue.

Each question is numerically coded and then scored on a scale of 0 to 100; higher values reflect better QOL. It also includes an item about health measured on a scale of 0-10, where 0 indicates "worst possible health (as bad as or worse than being dead)" and 10 indicates "best possible health."

\section{Statistical methods}

Data are presented as means \pm standard deviation. Categorical variables are shown as percentages. The Pearson correlation coefficient was used for independent quantitative variables, the Mann-Whitney $U$ test for dichotomous qualitative variables, and the ANOVA test for qualitative variables with three or more categories.

In order to explore how each sociodemographic and clinical characteristic influences QOL, a multiple linear regression analysis was performed. KDSC, PCS, and MCS were the outcome variables and backward stepwise selection was used for independent variables with an entry criterion of $p<0.05$ and an exit criterion of $p>0.1$. $\beta$-coefficients were calculated with the respective $95 \%$ confidence intervals.

The level of statistical significance was established as $p<0.05$. All data were analyzed using the SPSS statistical software package for Windows, version 15.0 (SPSS Inc., Chicago, III., USA).

\section{Results}

A total of $120 \mathrm{HD}$ patients with a mean age of $68 \pm 16$ years were included. Diabetes mellitus (DM) was the most frequent etiology of kidney disease. Sixty-seven percent of participants were male. According to the Barthel Index, $52 \%$ were classified as dependent for activities of daily living. Other relevant sociodemographic and clinical characteristics are described in Table 1. 


\section{Sociodemographic characteristics}

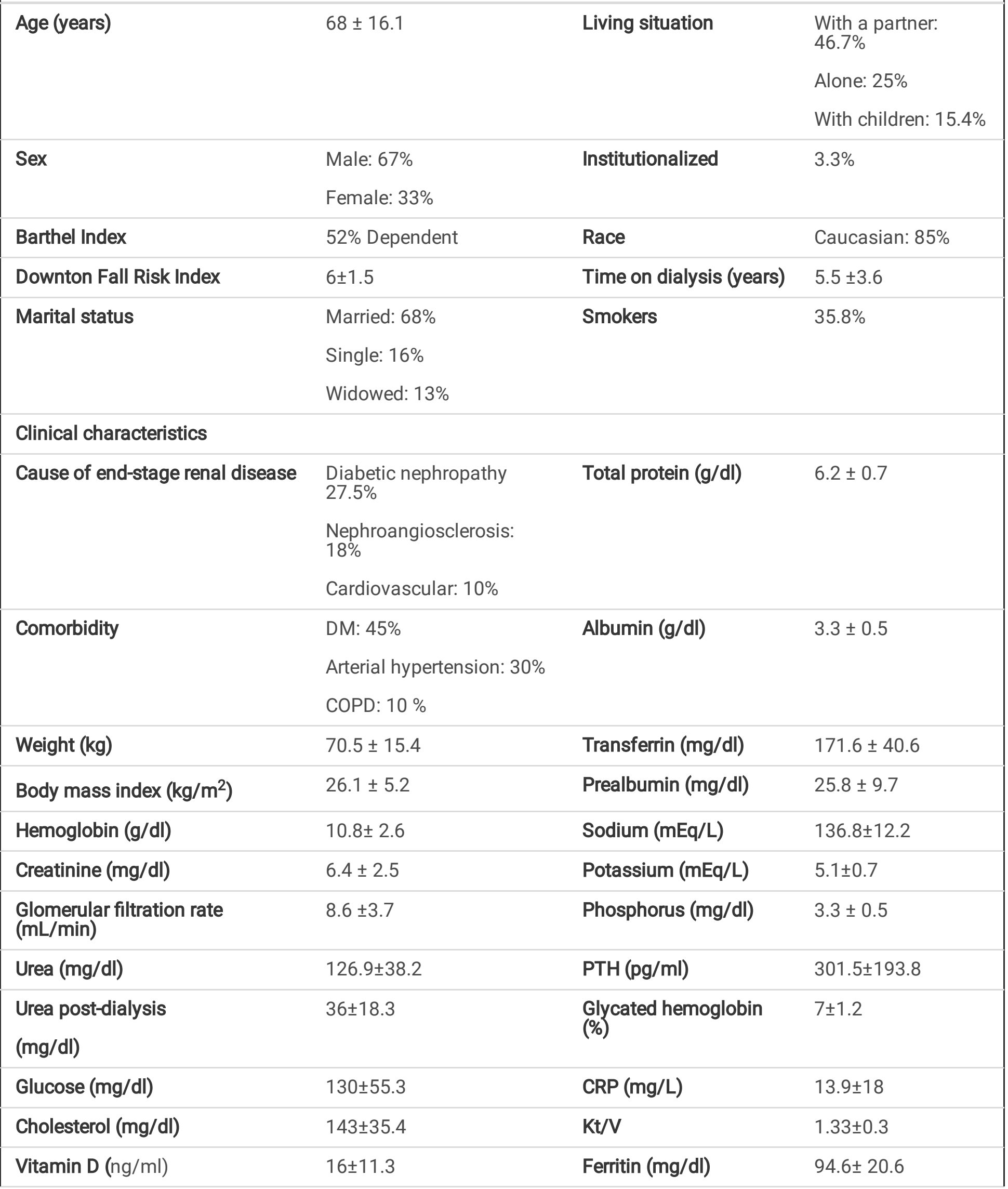




\section{Sociodemographic characteristics}

Data are expressed as mean \pm standard deviation for normal data. DM: Diabetes Mellitus. COPD: chronic obstructive pulmonary disease. CRP: C-reactive protein. PTH: Parathyroid hormone.

The mean MIS scale score was $8.4 \pm 3.5$ and $62 \%$ of patients were found to be at NR (MIS $>5)$. After the screening, a nutritional assessment was conducted and malnutrition was detected in $55 \%$. Of them, nearly $20 \%$ presented with severe protein-energy malnutrition (Figure 1). All patients received nutritional counseling which consisted of personalized diets and nutritional recommendations. In addition to these measures, $58 \%$ of patients needed additional supplementation to improve their nutritional status: $37 \%$ needed supplemental oral nutrition, $16 \%$ needed modular protein supplements, and $5 \%$ needed intradialytic parenteral nutrition.

All patients responded to the KDQOL-SF ${ }^{\mathrm{TM}}$ version 1.2 questionnaire while being monitored by trained staff. Despite monitoring, some questions were left unanswered; the most commonly unanswered questions were items related to sexual function. The different dimensions were classified in two groups based on the total scores. The areas that had higher scores ( $>80$ ) were quality of social interaction, dialysis staff encouragement, and patient satisfaction with the care received. Lower scores $(<50)$ were found on effects of kidney disease, burden of kidney disease, sexual function, cognitive function, sleep, and work status. On the specific part, the mean KDSC score was $56 \pm 10$ points. On the generic part (SF-36), the area with the highest score was emotional well-being and those with lower scores were physical functioning, role-physical, energy/fatigue, and general health. The PCS and MCS had a total score $<50$.

Fluid and dietary restrictions are two aspects that are bothersome in the daily life of HD patients and these aspects are inquired about in the effects of kidney disease dimension. Ninety percent of patients reported some degree of being bothered by fluid restrictions and $92 \%$ indicated being bothered by dietary restrictions; $25 \%$ and $20 \%$ of patients, respectively, indicated they were extremely bothered on these items.

The MIS and nutritional status were compared to scores on the KDQOL-SF ${ }^{\mathrm{TM}}$ components (Table 2). Patients who had an MIS score $\leq 5$ and well-nourished patients had higher scores on the QOL final summary components $(p<0.001)$. In terms of the different sub-scales of this questionnaire, on the KDSC, the areas that received significantly better scores among these patients were symptoms/problem list $(p<0.001)$, effects of kidney disease $(p<0.001)$, burden of kidney disease $(p<0.001)$, work status $(p<0.05)$, and sleep $(p<0.001)$. As for SF-36 components, all areas had significantly higher scores among patients who met these criteria $(p<0.001)$.

Table 2

Scores on the general summary areas according to MIS scale scores and nutritional status.

\begin{tabular}{|c|c|c|c|c|c|c|}
\hline \multirow[t]{2}{*}{ MIS score } & \multirow[b]{2}{*}{$\begin{array}{l}\text { MIS } \leq \text { NIP5 } \\
(n=46)\end{array}$} & \multicolumn{5}{|c|}{ Nutritional status } \\
\hline & & $\begin{array}{l}M I S>5 \\
(n=74)\end{array}$ & $\begin{array}{l}\mathrm{p} \\
\text { value }\end{array}$ & $\begin{array}{l}\text { Well- } \\
\text { nourished } \\
(n=54)\end{array}$ & $\begin{array}{l}\text { Malnourished } \\
(n=66)\end{array}$ & $\begin{array}{l}\mathrm{p} \\
\text { value }\end{array}$ \\
\hline $\begin{array}{l}\text { Kidney disease summary } \\
\text { component }\end{array}$ & $62.2 \pm 10.4$ & $52.6 \pm 8.3$ & $<0.001$ & $61.7 \pm 10.2$ & $51.9 \pm 7.9$ & $<0.001$ \\
\hline Physical component summary & $45.8 \pm 11.6$ & $34.3 \pm 12.3$ & $<0.001$ & $46.5 \pm 11.6$ & $32.4 \pm 11.1$ & $<0.001$ \\
\hline Mental component summary & $48.4 \pm 8.5$ & $41 \pm 10.0$ & $<0.001$ & $47.8 \pm 8.7$ & $40.5 \pm 10.1$ & $<0.001$ \\
\hline
\end{tabular}


A multiple linear regression analysis was performed with KDSC, PCS, and MCS as response variables (Table 3). Six explanatory variables were included: age, sex, malnutrition, Barthel Index, and the two main comorbidities: DM and COPD. Malnutrition adjusted for the Barthel Index and COPD showed the highest level of explanation on the KDSC $(\beta=-8.3, p<0.001)$, explaining $28.9 \%$ of the variance; the PCS adjusted for the Barthel Index $(\beta=-11.7, p<0.001)$, explaining $33 \%$ of the variance; and the MCS adjusted for sex (female) and age ( $\geq 70$ years) $(\beta=-7.2, p<0.001)$, explaining $21.5 \%$ of the variance. The comorbidity of DM was not significant predictor of either KDSC, PCS, or MCS $(p>0.05)$.

In summary, the results of the multiple regression analyses showed that malnutrition was the most prominent predictor of lower scores on the KDQOL-SF ${ }^{\mathrm{TM}}$ among our HD population.

Table 3

Scores on the general summary areas according to MIS scale score and nutritional status.

\begin{tabular}{|c|c|c|c|c|c|c|c|c|c|}
\hline \multirow[t]{2}{*}{ KDSC } & \multicolumn{6}{|c|}{ PCS } & \multicolumn{3}{|l|}{ MCS } \\
\hline & $\begin{array}{l}\beta \\
\text { coefficient }\end{array}$ & $\begin{array}{l}\mathrm{P} \\
\text { value }\end{array}$ & $\begin{array}{l}95 \% \\
\mathrm{Cl}\end{array}$ & $\begin{array}{l}\beta \\
\text { coefficient }\end{array}$ & $\begin{array}{l}P \\
\text { value }\end{array}$ & $\begin{array}{l}95 \% \\
\mathrm{Cl}\end{array}$ & $\begin{array}{l}\beta \\
\text { coefficient }\end{array}$ & $\begin{array}{l}\mathrm{P} \\
\text { value }\end{array}$ & $\begin{array}{l}95 \% \\
\mathrm{Cl}\end{array}$ \\
\hline $\begin{array}{l}\text { Nutritional } \\
\text { status } \\
\text { (Malnutrition) }\end{array}$ & -8.38 & $<0.001$ & $\begin{array}{l}-11.87 \\
\text { to } \\
4.89\end{array}$ & -11.77 & $<0.001$ & $\begin{array}{l}-16.12 \\
\text { to } \\
7.42\end{array}$ & -7.26 & $<0.001$ & $\begin{array}{l}-10.64 \\
\text { to } \\
3.91\end{array}$ \\
\hline $\begin{array}{l}\text { Barthel Index } \\
\text { (Independent) }\end{array}$ & 3.08 & 0.088 & $\begin{array}{l}-0.46 \\
\text { to } \\
6.63\end{array}$ & 6.43 & 0.005 & $\begin{array}{l}2.02 \\
\text { to } \\
10.84\end{array}$ & NA & & \\
\hline $\begin{array}{l}\text { COPD } \\
\text { (Presence) }\end{array}$ & -7.44 & 0.009 & $\begin{array}{l}-13.0 \\
\text { to } \\
-1.89\end{array}$ & NA & & & NA & & \\
\hline $\begin{array}{l}\text { Sex } \\
\text { (Female) }\end{array}$ & NA & & & NA & & & -5.73 & 0.002 & $\begin{array}{l}-9.24 \\
\text { to } \\
-2.22\end{array}$ \\
\hline $\begin{array}{l}\text { Age } \\
\text { ( } \geq 70 \text { years) }\end{array}$ & NA & & & NA & & & 3.22 & 0.061 & \\
\hline $\begin{array}{l}\text { DM } \\
\text { (Presence) }\end{array}$ & NA & & & NA & & & NA & & \\
\hline
\end{tabular}

\section{Discussion}

In this cross-sectional study, we observed that the presence of malnutrition was the most consistent independent determinant of decreased health-related QOL in HD patients as assessed by the KDQOL-SF ${ }^{\mathrm{TM}}$.

Malnutrition and impaired QOL are prevalent conditions among HD patients. Malnutrition can lead to PEW syndrome, which entails a loss of muscle mass and depletion of energy deposits that can cause difficulties in performing the basic activities of daily living and may reduce an individual's strength and autonomy, which in turn can reduce QOL. 
Recommendations and guidelines have been issued for the inclusion of nutritional management in the comprehensive approach to this disease [6]. Thus, it is important to evaluate patients' nutritional status. Although a gold standard screening technique for detecting malnutrition in HD patients has not been established, higher MIS scores have been associated with poorer nutritional status and higher hospitalization and mortality rates[16]. We evaluated the applicability of the MIS in HD patients and found that $62 \%$ of the study population was at NR. These results are in line with the findings of other studies $[17,18]$, but the percentage of NR found in our work is considerably higher than what has been reported previously $[19,20,21]$. However, these prior studies used the SGA screening method. Although SGA is reported to perform well in hospitalized patients, the MIS method was specifically designed to detect the NR in HD outpatients [7], making it a highly reliable and effective screening tool for assessing NR in this population. The different instruments used may explain the higher rate of NR found in our work.

The presence of NR does not necessary indicate malnutrition, but rather refers to the risk of developing it. In fact, our results demonstrated that $7 \%$ of patients at NR were in fact classified as well-nourished. This highlights the importance of implementing a personalized NIP early in order to prevent further deterioration in nutritional status.

It has been demonstrated that MIS correlates with QOL domains as assessed by the KDQOL-SF ${ }^{\mathrm{TM}}$ tool [22]. In our study, after having analyzed the study population's QOL, we compared it to different variables related to nutritional status. This comparison showed impaired QOL in patients at NR and malnourished patients. Patients with these criteria had lower scores on effects of kidney disease, an area which includes questions about fluid and dietary restrictions. One possible explanation is the fact that a dialysis diet is among the most restrictive diets and these restrictions may cause frustration, represent a significant burden, and lead to suboptimal treatment adherence which in turn may worsen patients' QOL and satisfaction [23, 24].

Many cross-sectional studies have observed poorer QOL outcomes in HD patients compared to well-nourished patients. These studies use different tools to assess nutritional status and QOL [4, 25]. A work by Günalay S et al. [26] that used the Mini Nutritional Assessment - Short Form to determine nutritional status demonstrated that QOL scores as measuring by the EQ5D questionnaire decreased as malnutrition rates increased. Uy MC et al. [27] studied the relationship between malnutrition and QOL among patients with DM on maintenance HD using the Dialysis Malnutrition Score (DMS) and the World Health Organization Quality of Life (WHOQoL)-BREF questionnaire. They found that those who were malnourished as per the DMS showed a significantly lower physical $(p<0.001)$, psychological $(p<0.001)$, and social QOL $(p=0.004)$.

A prospective research study by Viramontes-Hörner D et al. [28] investigated this association over time and demonstrated that at baseline, malnutrition as assessed by SGA was the only factor independently and negatively associated with QOL, as assessed by the SF-36 and EQ5D questionnaires. They also reported low MCS and PCS scores $(<50)$ compared to our study population. Several other researchers have also explored the relationship between nutritional status and QOL. They also demonstrated that QOL scores decrease as malnutrition rates increase [29, 30]. One strength of our study with respect to previous works is that our work adds to the published data by showing that malnutrition was an independent determinant of decreased QOL on the kidney-specific QOL domains of the KDQOL-SF ${ }^{\mathrm{T} M}$ questionnaire.

Nutritional counseling and treatment provided through a NIP have been associated with improved QOL in CKD patients [31, 32]. In this regard, a study by Aghakhani $\mathrm{N}$ et al. [33] divided their HD study population into two groups: one group which received nutritional counseling and another, the control group, which did not. This study concluded that patients who received nutritional counseling had a significant improvement in their QOL. Campbell et al. [5] demonstrated that in pre-HD patients, improvements in nutritional status in the intervention group translated into significant improvements in the symptoms, cognitive functioning, and vitality subscales assessed by KDQOL ${ }^{\mathrm{TM}}$ v1.3. Scott MK et 
al. [34] designed a prospective study where showed that oral nutritional supplementation significantly improved serum albumin and the role-physical domain score of the KDQOL-SF ${ }^{\mathrm{TM}}$ survey over time versus the comparator arm. In our study, $53 \%$ of patients needed nutritional supplements as a part of their treatment. However, as this is a cross-sectional study, we cannot definitively demonstrate that this measure improved their nutritional status and QOL.

These findings underscore the need to implement nutritional screening and monitoring to identify HD patients at NR or to detect malnutrition early and implement an appropriate NIP in order to prevent malnutrition and improve nutritional status.

\section{Conclusions}

Our study found that malnutrition is one of the most prominent factors affecting QOL. Several previous works have shown the importance of establishing nutritional support through the implementation of a NIP and the use of the MIS as an effective, sensitive screening tool for detecting NR. The high rate of NR observed in our work and the importance of detecting malnutrition in early stages highlight the need to identify at-risk patients early in order to change the timing and type of interventions, personalizing them to improve efficacy. Knowing each patient's weaknesses on certain areas of the QOL questionnaire allows us to develop and implement new strategies to help patients to improve their general and specific perceptions of QOL. Our findings are supported by other works, but additional studies are needed to further support these assertions.

\section{Practical Application}

In this study, we showed that malnutrition is a frequent condition in HD patients and the most powerful factor affecting these patients' QOL. The use of a reliable screening tool followed by a personalized NIP reduced the risk of developing malnutrition and treatment in early stages improves these patients' QOL. In view of these findings, early detection of malnutrition and a NIP should be implemented in those who require it. Further long-term observation is needed to assess the potential effects of a NIP on HD patients.

\section{Declarations}

\section{Acknowledgments:}

We thank the staff of the Nephrology, Pharmacy \& Nutrition and Research \& Innovation Departments at the Costa del Sol Hospital for their intellectual and direct contributions to this study, which forms part of a Ph.D. research program being conducted at the University of Granada (Spain).

\section{Author Contributions:}

Conceptualization, Jimena Abiles and Francisca Lopez; Data curation, Lucia Visiedo, Laura Rey; Formal analysis, Francisco Rivas; Investigation, Lucia Visiedo and Laura Rey; Methodology, Lucia Visiedo, Francisco Rivas and Jimena Abiles; Project administration, Francisca Lopez; Software , Francisco Rivas; Supervision, Jimena Abiles; Validation, Begoña Tortajada, Rafael Gimenez and Jimena Abiles; Visualization, Francisco Rivas; Writing - original draft, Lucia Visiedo; Writing - review \& editing, Lucia Visiedo.

\section{Funding:}


This research did not receive any specific grant from funding agencies in the public, commercial, or not-for-profit sectors

\section{Conflicts of Interest:}

The authors declare no conflict of interest.

\section{References}

1. Garrido Pérez, L., Sanz Turrado, M. \& Caro Domínguez, C. Variables de la desnutrición en pacientes en diálisis. Enferm Nefrol, 19 (4), 307-316 (2016).

2. Kuhlmann, M. K., Kribben, A., Wittwer, M. \& Hörl, W. H. OPTA-Malnutrition in chronic renal failure. Nephrol Dial Transplant, 22 (suppl_3), iii13-iii19 (2007).

3. Nagy, E., Mahmoud, M., El-Kannishy, G. \& Sayed-Ahmed, N. Impact of malnutrition on health-related quality of life in patients on maintenance hemodialysis. Ther Apher Dial Off peer-reviewed J Int Soc Apher Japanese Soc Apher Japanese Soc Dial Ther, 25 (4), 467-474 (2021 Aug).

4. Sohrabi, Z., Eftekhari, M. H., Eskandari, M. H., Rezaeianzadeh, A. \& Sagheb, M. M. Malnutrition-inflammation score and quality of life in hemodialysis patients: is there any correlation? Nephrourol Mon. 2015 May;7(3):e27445

5. Campbell, K. L., Ash, S. \& Bauer, J. D. The impact of nutrition intervention on quality of life in pre-dialysis chronic kidney disease patients.Clin Nutr. 2008Aug;27(4):537-44.

6. Ikizler, T. A. et al. KDOQI Clinical Practice Guideline for Nutrition in CKD: 2020 Update Vol. 76p. S1-107(American journal of kidney diseases: the official journal of the National Kidney Foundation. United States, 2020).

7. Kalantar-Zadeh, K., Kleiner, M., Dunne, E., Lee, G. H. \& Luft, F. C. A modified quantitative subjective global assessment of nutrition for dialysis patients. Nephrol Dial Transplant, 4 (7), 1732-1738 (1999).

8. Detsky, A. S. et al. What is subjective global assessment of nutritional status? JPEN J Parenter Enteral Nutr, 11 (1), 8-13 (1987).

9. Amparo, F. C. et al. Diagnostic validation and prognostic significance of the Malnutrition-Inflammation Score in nondialyzed chronic kidney disease patients. Nephrol Dial, 30 (5), 821-828 (2015 May).

10. Molnar, M. Z. et al. Association of the malnutrition-inflammation score with clinical outcomes in kidney transplant recipients. Am J kidney Dis Off J Natl Kidney Found, 58 (1), 101-108 (2011 Jul).

11. Kalantar-Zadeh, K., Kopple, J. D., Block, G. \& Humphreys, M. H. A malnutrition-inflammation score is correlated with morbidity and mortality in maintenance hemodialysis patients. Am J kidney Dis Off J Natl Kidney Found, 38 (6), 1251-1263 (2001 Dec).

12. Rambod, M. et al. Association of Malnutrition-Inflammation Score with quality of life and mortality in hemodialysis patients: a 5-year prospective cohort study. Am J kidney Dis Off J Natl Kidney Found, 53 (2), 298309 (2009 Feb).

13. He, T. et al. Malnutrition-inflammation score predicts long-term mortality in Chinese PD patients. Clin Nephrol, 79 (6), 477-483 (2013 Jun).

14. Kovesdy, C. P. \& Kalantar-Zadeh, K. Why is protein-energy wasting associated with mortality in chronic kidney disease? Semin Nephrol. 2009 Jan;29(1):3-14.

15. Hays, R. D. et al. Kidney disease quality of life short form (KDQOL-SF), version 1.2: A manual for use and scoring (Spanish Questionnaire, Spain). P-7928/1 (RAND, Santa Monica, CA, 1997). 
16. Wang, W-L. et al. Association of the malnutrition-inflammation score with anthropometry and body composition measurements in patients with chronic kidney disease. Ann Palliat Med, 8 (5), 596-603 (2019 Nov).

17. Brandão da Cunha Bandeira, S., Cansanção, K., Pereira de Paula, T. \& Peres, W. A. F. Evaluation of the prognostic significance of the malnutrition inflammation score in hemodialysis patients. Clin Nutr ESPEN, 35, 109-115 (2020 Feb).

18. Aggarwal, H. K., Jain, D., Chauda, R., Bhatia, S. \& Sehgal, R. Assessment of Malnutrition Inflammation Score in Different Stages of Chronic Kidney Disease. Pril (Makedonska Akad na Nauk i Umet Oddelenie za Med Nauk. 2018 Dec;39(2-3):51-61.

19. Gencer, F., Yıldıran, H. \& Erten, Y. Association of Malnutrition Inflammation Score With Anthropometric Parameters, Depression, and Quality of Life in Hemodialysis Patients. J Am Coll Nutr, 38 (5), 457-462 (2019 Jul).

20. Rezeq, H. A., Khdair, L. N., Hamdan, Z. I. \& Sweileh, W. M. Prevalence of malnutrition in hemodialysis patients: A single-center study in Palestine. Saudi J kidney Dis Transplant an Off Publ Saudi Cent Organ Transplantation. Saudi Arab, 29 (2), 332-340 (2018).

21. Akhlaghi, Z. et al. Assessment of nutritional status in maintenance hemodialysis patients: A multicenter crosssectional study in Iran. Semin Dial, 34 (1), 77-82 (2021 Jan).

22. de Roij, C. L. M. et al. Comparing Tests Assessing Protein-Energy Wasting: Relation With Quality of Life. J Ren Nutr Off J Counc Ren Nutr Natl Kidney Found, 26 (2), 111-117 (2016 Mar).

23. Kalantar-Zadeh, K. et al. Dietary restrictions in dialysis patients: is there anything left to eat? Semin Dial, 28 (2), 159-168 (2015).

24. Palmer, S. C. et al. Dietary and fluid restrictions in CKD: a thematic synthesis of patient views from qualitative studies. Am J kidney Dis Off J Natl Kidney Found, 65 (4), 559-573 (2015 Apr).

25. Hafi, E. et al. Nutritional status and quality of life in diabetic patients on hemodialysis: a cross-sectional study from Palestine. J Health Popul Nutr, 40 (1), 30 (2021 Jul).

26. Günalay, S., Öztürk, Y. K., Akar, H. \& Mergen, H. The relationship between malnutrition and quality of life in haemodialysis and peritoneal dialysis patients. Rev Assoc Med Bras, 64 (9), 845-852 (2018 Sep).

27. Uy, M. C., Lim-Alba, R. \& Chua, E. Association of Dialysis Malnutrition Score with Hypoglycemia and Quality of Life among Patients with Diabetes on Maintenance hemodialysis. J ASEAN Fed Endocr Soc, 33 (2), 137-145 (2018).

28. Viramontes-Hörner, D., Pittman, Z., Selby, N. M. \& Taal, M. W. Impact of malnutrition on health-related quality of life in persons receiving dialysis: a prospective study. Br J Nutr. 2021 Jul;1-24.

29. Kvamme, J-M., Olsen, J. A., Florholmen, J. \& Jacobsen, B. K. Risk of malnutrition and health-related quality of life in community-living elderly men and women: the Troms $\varnothing$ study. Qual life Res an Int J Qual life Asp Treat care Rehabil. 2011 May;20(4):575-82.

30. Nagy, E., Mahmoud, M., El-Kannishy, G. \& Sayed-Ahmed, N. Impact of malnutrition on health-related quality of life in patients on maintenance hemodialysis. Ther Apher Dial Off peer-reviewed J Int Soc Apher Japanese Soc Apher Japanese Soc Dial Ther, 25 (4), 467-474 (2021 Aug).

31. Magalhães, F. G., Goulart, R. M. M. \& Prearo, L. C. The impact of a nutrition intervention program targeting elderly people with chronic kidney disease. Cien Saude Colet, 23 (8), 2555-2564 (2018 Aug).

32. Lodebo, B. T., Shah, A. \& Kopple, J. D. Is it Important to Prevent and Treat Protein-Energy Wasting in Chronic Kidney Disease and Chronic Dialysis Patients? J Ren Nutr Off J Counc Ren Nutr Natl Kidney Found. 2018 Nov;28(6):36979.

33. Aghakhani, N., Samadzadeh, S., Mafi, T. M. \& Rahbar, N. The impact of education on nutrition on the quality of life in patients on hemodialysis: a comparative study from teaching hospitals. Saudi J kidney Dis Transplant an Off

Page $11 / 12$ 
Publ Saudi Cent Organ Transplantation, Saudi Arab. 2012 Jan;23(1):26-30.

34. Scott, M. K. et al. Effects of peridialytic oral supplements on nutritional status and quality of life in chronic hemodialysis patients. J Ren Nutr Off J Counc Ren Nutr Natl Kidney Found, 19 (2), 145-152 (2009 Mar).

\section{Figures}

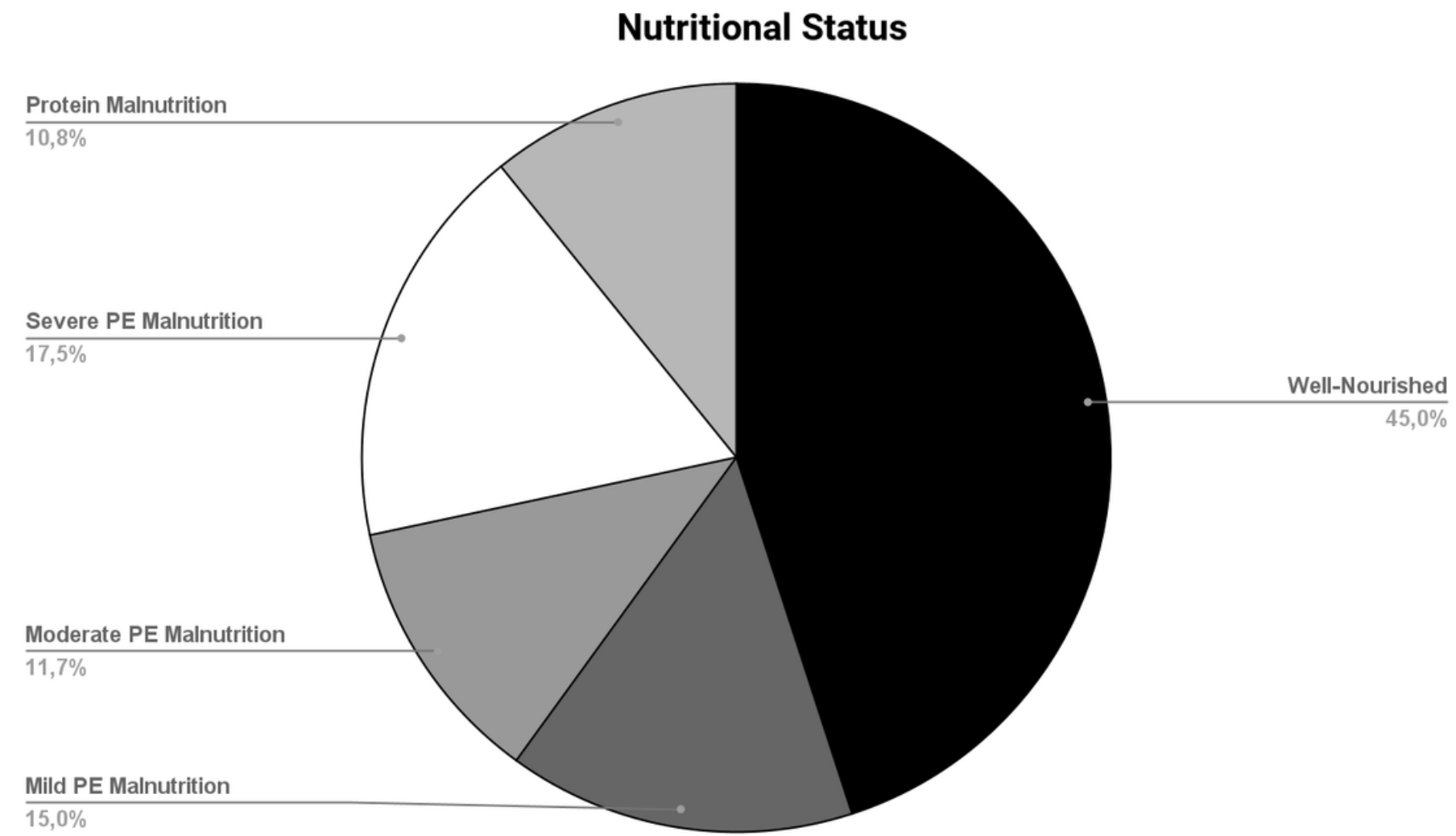

Figure 1

Nutritional Status Nutritional status. Data are expressed as percentages. PE: Protein-Energy. 